\title{
Validation of the Atopic Dermatitis Control Tool (ADCTC) using a longitudinal survey of biologic-treated patients with atopic dermatitis
}

Eric Simpson ${ }^{1}$, Laurent Eckert ${ }^{2 *}$, Abhijit Gadkari ${ }^{3}$, Usha G. Mallya ${ }^{4}$, Min Yang ${ }^{5}$, Lauren Nelson ${ }^{6}$, Michelle Brown ${ }^{6}$, Matt Reaney ${ }^{7}$, Puneet Mahajan $^{8}$, Isabelle Guillemin ${ }^{2}$, Mark Boguniewicz ${ }^{9}$ and David Pariser ${ }^{10}$

\begin{abstract}
Background: The Atopic Dermatitis Control Tool (ADCTO) is a brief patient self-administered instrument designed and validated to assess atopic dermatitis (AD) control; six AD symptoms and impacts are evaluated over the past week, including overall severity of symptoms, days with intense episodes of itching, intensity of bother, problem with sleep, impact on daily activities, and impact on mood or emotions. This study assessed the reliability, validity, and responsiveness of the ADCT in a longitudinal context, and provided thresholds to identify meaningful withinperson change.

Methods: Data were from a prospective, longitudinal patient survey study of real-world effectiveness of dupilumab in patients with AD. Eligible patients completed a baseline survey before starting dupilumab and were followed at Months 1, 2, 3, and 6 post-initiation as they became eligible.

Results: Psychometric analyses confirmed internal consistency; Cronbach's a coefficients were consistently above the threshold of 0.70 across each follow-up; item-to-total correlations were above the threshold of $r \geq 0.50$. High correlations between the ADCT and the Dermatology Life Quality Index (DLQI) and skin pain supported construct validity, while known-group validity was shown on Patient Global Assessment of Disease (PGAD) overall well-being subgroups with worse AD-related overall well-being having higher mean ADCT total scores at all time points. The ability of the ADCT to detect change was confirmed; the threshold for meaningful within-person change was estimated to be 5 points. Finally, test-retest reliability was confirmed in subgroups of patients with stable PGAD responses.
\end{abstract}

Conclusions: Our findings confirm that the ADCT is a valid and reliable tool for assessing AD control.

Keywords: Atopic dermatitis, tool, control, symptoms, impacts, ADCT®, reliability, validity, responsiveness

\section{Background}

Atopic dermatitis (AD) is a systemic, inflammatory skin condition $[1,2]$ characterized by intense pruritus, eczematous lesions, swelling, and pain [3-6]. With increasing awareness of the substantial patient burden associated with long-term uncontrolled $\mathrm{AD}$ [3, 7-13], especially as it relates to sleep disturbance, healthrelated quality of life, and work or school performance

\footnotetext{
* Correspondence: Laurent.Eckert@sanofi.com

${ }^{2}$ Sanofi, France, Chilly-Mazarin, Paris, France

Full list of author information is available at the end of the article
}

[6, 14-19], assessment of patient self-reported disease control has been deemed crucial for clinical evaluation of $\mathrm{AD}[15,20,21]$.

Several patient-reported outcome measures (PROMs), including the Peak Pruritus Numerical Rating Scale (Peak Pruritus NRS) [22] for itch, the Patient-Oriented Eczema Measure (POEM) [23] for overall AD symptoms, and the Dermatology Life Quality Index (DLQI) [24] for health-related quality of life (HRQL), are available for use in AD trials; however, these PROMs do not holistically capture the broad concept of disease control. AD

(c) The Author(s). 2019 Open Access This article is distributed under the terms of the Creative Commons Attribution 4.0 International License (http://creativecommons.org/licenses/by/4.0/), which permits unrestricted use, distribution, and reproduction in any medium, provided you give appropriate credit to the original author(s) and the source, provide a link to the Creative Commons license, and indicate if changes were made. The Creative Commons Public Domain Dedication waiver (http://creativecommons.org/publicdomain/zero/1.0/) applies to the data made available in this article, unless otherwise stated. 
control has been described in various ways in the literature, ranging from reduced disease severity or the absence of $\mathrm{AD}$ flares, to the impact of $\mathrm{AD}$ on patients' everyday lives and well-being [25-29].

The Atopic Dermatitis Control Tool (ADCT๔) is a new PROM designed to assess patient-perceived disease control, meeting this current measurement gap in the management of patients with AD (ADCT v1; https:// patient-questionnaires.sanofi.com/questionnaires/adctatopic-dermatitis-control-communication-tool) (Pariser D, Simpson E, Gadkari A, Bieber T, Margolis D, Brown M, Nelson L, Mahajan P, Reaney M, Guillemin I et al: Design, validation and scoring of the Atopic Dermatitis Control Tool (ADCT), unpublished). It is envisaged that the tool will also foster patient-clinician communication regarding disease control. The ADCT is a simple, brief tool that evaluates six symptoms and effects associated with $\mathrm{AD}$ over the past week. These include overall severity of symptoms, days with intense episodes of itching, intensity of bother, problem with sleep, impact on daily activities, and impact on mood or emotions. Each of the six ADCT items has a score range from 0 (no problem) to 4 (worst), rating the severity of each concept; the total score ranges from 0 to 24 , which is the summation of the responses to all the items. An initial evaluation of the psychometric properties of the instrument in the United States has indicated that the ADCT is valid and reliable for assessing patient-perceived $A D$ control in adults (Pariser D, Simpson E, Gadkari A, Bieber T, Margolis D, Brown M, Nelson L, Mahajan P, Reaney M, Guillemin I et al: Design, validation and scoring of the Atopic Dermatitis Control Tool (ADCT), unpublished). In addition, a score of $\geq 7$ points was derived as the threshold to identify patients "not in control", based on optimal sensitivity/specificity values (Pariser D, Simpson E, Gadkari A, Bieber T, Margolis D, Brown M, Nelson L, Mahajan P, Reaney M, Guillemin I et al: Design, validation and scoring of the Atopic Dermatitis Control Tool (ADCT), unpublished). The ADCT $\odot$ is protected by copyright with all rights reserved to Sanofi and its development partners.

The present study further assessed the reliability, validity, and responsiveness of the ADCT. In addition, it defines a threshold to identify meaningful within-person change. The assessments were conducted on data from the EaRly REal-WorLd PatIent EValuation for DupixEnt in Atopic Dermatitis (RELIEVE-AD) study, a prospective, longitudinal patient survey conducted in the United States that aims to evaluate the early effectiveness of dupilumab in the real-world setting. Dupilumab is approved in the United States and Japan for subcutaneous administration every 2 weeks for the treatment of patients aged $\geq 12$ years with moderate-to-severe AD inadequately controlled with topical prescription therapies or when those therapies are not advisable [30], and in the European Union for use in adults with moderate-tosevere $\mathrm{AD}$ who are candidates for systemic therapy [31].

\section{Methods}

Data source

RELIEVE-AD is an ongoing observational, prospective, longitudinal survey study in adult patients with $\mathrm{AD}$ who were enrolled in the Dupixent MyWay ${ }^{\text {tm }}$ Patient Support Program and for whom dupilumab had been recently prescribed. Eligible patients completed a baseline survey before starting dupilumab and were followed at Months 1, $2,3,6,9$, and 12 post-initiation as they become eligible.

Patient enrollment into the RELIEVE-AD study began in January 2018 and the final data collection is expected to be completed in February 2020. The present study included patients in the RELIEVE-AD study who, on December 6, 2018, had completed the baseline and Months 1, 2, 3, and 6 surveys. Patients were eligible for inclusion in the RELIEVE-AD study if they met the following criteria at the time of the baseline survey:

- aged $\geq 18$ years

- can speak and read English

- be willing to participate in the study and provide informed consent

- have not previously participated in a dupilumab clinical trial

- have not initiated treatment with dupilumab.

The surveys collected data on patient characteristics, including socio-demographics (age, sex, race/ethnicity, marital status, level of education, insurance, employment status, level of income, geographic region), medical history (self-reported age at AD diagnosis, comorbidities), and $\mathrm{AD}$ treatment and experience (treatment history prior to dupilumab initiation, concomitant therapy post dupilumab initiation, self-reported adherence to treatment and reasons for discontinuation), and treatment satisfaction.

In addition, PRO data were collected using the Patient Global Assessment of Disease (PGAD), Numerical Rating Scale (NRS) for patient self-reported symptoms (skin pain, burning, and sensitivity) (scores: 0-10; higher scores indicate worse symptom severity), disease control using ADCT (eczema-related symptoms, days with intense itching, overall bothersomeness, sleep problems, daily activities, mood/emotion; total score 0-24; higher scores indicate worse disease control), health-related quality of life (HRQL) using the Dermatology Life Quality Index (DLQI: 0-30, higher scores indicating worse HRQL), and the Work Productivity and Activity Impairment-Atopic Dermatitis questionnaire (WPAIAD; percentages: $0-100$, higher percentages indicate greater impairment) for patients in employment. (Table 1). 
Table 1 Patient-reported outcome measures used in RELIEVE-AD

\begin{tabular}{|c|c|c|c|c|c|}
\hline Questionnaires & $\begin{array}{l}\text { Items } \\
(\#)\end{array}$ & Item content & Response options & $\begin{array}{l}\text { Recall } \\
\text { period }\end{array}$ & Score ranging and direction definition \\
\hline $\begin{array}{l}\text { Atopic Dermatitis Control Tool } \\
\text { (ADCT) }\end{array}$ & 6 & $\begin{array}{l}\text { Overall severity of } \\
\text { symptoms } \\
\text { Days with intense } \\
\text { episodes of } \\
\text { itching } \\
\text { Intensity of } \\
\text { bothersomeness } \\
\text { Problem with } \\
\text { sleep } \\
\text { Impact on daily } \\
\text { activities } \\
\text { Impact on mood } \\
\text { or emotions }\end{array}$ & $\begin{array}{l}\text { None, Mild, Moderate, Severe, Very } \\
\text { severe } \\
\text { Not at all, 1-2 days/nights, 3-4 days/ } \\
\text { nights, 5-6 days/nights, Every day/Every } \\
\text { night } \\
\text { Not at all, A little, Moderately, Very/A lot, } \\
\text { Extremely }\end{array}$ & $\begin{array}{l}\text { Past } \\
\text { week }\end{array}$ & $\begin{array}{l}\text { Item scores ranging from } 0 \text { to } 4 \\
\text { Total score ranging from } 0 \text { (i.e., best disease } \\
\text { control) to } 24 \text { (i.e., worst disease control) } \\
\text { ADCT total score }<7 \text { is considered as AD } \\
\text { controlled, whereas } \geq 7 \text { is considered AD is not } \\
\text { controlled }\end{array}$ \\
\hline Skin pain NRS & 1 & $\begin{array}{l}\text { Overall skin pain } \\
\text { or soreness }\end{array}$ & NA & $\begin{array}{l}\text { Past } \\
\text { week }\end{array}$ & $\begin{array}{l}\text { Scores ranging from } 0 \text { to } 10 \\
0=\text { No skin pain or soreness } \\
10=\text { Worst skin pain or soreness }\end{array}$ \\
\hline $\begin{array}{l}\text { Patient Global Assessment of Disease } \\
\text { (PGAD) overall well-being }\end{array}$ & 1 & $\begin{array}{l}\text { AD-related overall } \\
\text { well-being }\end{array}$ & Excellent, Very good, Good, Fair, Poor & $\begin{array}{l}\text { Past } \\
\text { week }\end{array}$ & NA \\
\hline $\begin{array}{l}\text { Dermatology Life Quality Index } \\
\text { (DLQI) }\end{array}$ & 10 & $\begin{array}{l}\text { Itch, pain, stinging } \\
\text { symptoms } \\
\text { Embarrassment } \\
\text { Activities of daily } \\
\text { living } \\
\text { Everyday life } \\
\text { (clothes to wear) } \\
\text { Social life } \\
\text { Sport activities } \\
\text { Work and } \\
\text { professional life } \\
\text { Relationships } \\
\text { Intimate life } \\
\text { Treatment on } \\
\text { everyday life }\end{array}$ & Very much, A lot, A little, Not at all & $\begin{array}{l}\text { Past } \\
\text { week }\end{array}$ & $\begin{array}{l}\text { Total score ranging from } 0 \text { (i.e., no effect on } \\
\text { patient's life) to } 30 \text { (i.e., largest effect on patient's } \\
\text { life) } \\
\text { Bands meaning: } \\
0-1=\text { no effect at all on patient's life } \\
2-5=\text { small effect on patient's life } \\
6-10=\text { moderate effect on patient's life } \\
11-20=\text { very large effect on patient's life } \\
21-30=\text { extremely large effect on patient's life }\end{array}$ \\
\hline $\begin{array}{l}\text { Work Productivity and Activity } \\
\text { Impairment - Atopic Dermatitis } \\
\text { (WPAI-AD) }\end{array}$ & 6 & $\begin{array}{l}\text { Absenteeism } \\
\text { Presenteeism } \\
\text { Total work } \\
\text { impairment } \\
\text { Total activity } \\
\text { impairment }\end{array}$ & $\begin{array}{l}\text { Multiple formats: Dichotomous Yes/No; } \\
\text { NRS; number of hours }\end{array}$ & $\begin{array}{l}\text { Past } 7 \\
\text { days }\end{array}$ & $\begin{array}{l}\text { Total score ranging from } 0 \% \text { impairment to } \\
100 \% \text { impairment }\end{array}$ \\
\hline
\end{tabular}

$A D$ Atopic dermatitis, NA Non-applicable, NRS Numerical rating scale

Analyses in this study were conducted using PRO data from multiple survey timepoints to ensure the robustness of the findings.

\section{Statistical methods}

All data analyses were conducted using SAS 9.4 (SAS Institute Inc., Cary, NC, USA).

\section{Reliability}

Assessments for reliability included internal consistency reliability and test-retest reliability. Internal consistency was assessed using Cronbach's alpha $(\alpha \geq 0.7)$ [32]. ADCT item-to-total correlations were estimated at baseline and Months 1, 2, 3, and 6 using the Pearson correlation coefficient $(\mathrm{PCC} \geq 0.5)$ [33]. Test-retest reliability was evaluated based on the intra-class correlation (ICC) coefficient of the ADCT total score among patients with unchanged PGAD scores across month pairs (between Months 1 and 2, Months 2 and 3, and Months 3 and 6). An ICC $\geq 0.70$ was expected for confirming test-retest reliability [34].

\section{Construct validity}

Convergent validity of the ADCT was assessed by computing Spearman's rank-order correlation between the ADCT total score and the DLQI (total and item-level scores), skin pain, PGAD overall well-being, WPAI total work impairment (WPAI-TWI), and WPAI total activity impairment (WPAI-TAI) at baseline and Months 1, 2, 3, and 6. Given that the skin pain NRS directly measures AD-related symptoms and the DLQI includes questions on both symptoms and impacts due to skin problems, correlations between the ADCT and skin pain and DLQI were expected to be higher than the correlations between the ADCT and other measures, such as PGAD, WPAI-TWI, and WPAI-TAI. Cohen's recommended guidelines for determining small, moderate, or large effects $(0.1$ to $<0.3,0.3$ to $<0.5$, and $\geq 0.5$, respectively) were applied, and a large effect $(r \geq 0.5)$ was used in this study as evidence of convergent validity [35]. Divergent validity, established previously for the ADCT, was not assessed here owing to the lack of appropriate measures for use from the current study. 


\section{Known-groups validity}

To confirm known-groups validity, mean ADCT total scores were compared across adjacent subgroups of patients based on PGAD responses (Excellent, Very good, Good, Fair, Poor) and categories of DLQI responses: no effect on patient life (score range: 0-1), a small effect (2-5), a moderate effect (6-10), a very large effect (11$20)$, or an extremely large effect (21-30) [36] (Table 1). Patients in a worse PGAD or DLQI band subgroup were expected to display poorer AD control (i.e., higher mean ADCT total scores, indicating more severe symptoms/ greater impact) than patients in a better PGAD or DLQI band subgroup. If the homogeneity of variance across the subgroups was rejected $(p<0.05)$ based on a Levene's test of equality of variance, a Mann-Whitney U test was used to compare the mean ADCT total scores between the subgroups; otherwise, $t$-tests were applied. Cohen's d was calculated for the standardized differences in mean ADCT total scores between subgroups and was corrected for small sample sizes when the total sample size in the two groups was below 50 [37].

\section{Ability to detect change (responsiveness)}

Responsiveness was evaluated using correlations between the change from baseline (to Months 1, 2, 3, and 6) in ADCT total score and the change from baseline in DLQI total score (Pearson product-moment). The same analysis was conducted using (Spearman's rankorder correlation) $(r \geq 0.5)$ for DLQI bands and PGAD scores [34].

\section{Interpretation of change}

Anchor-based and distribution-based methods were used to establish a threshold characterizing meaningful within-person change in the ADCT total score.

Prior to applying the anchor-based method, the correlation coefficient between the change in the ADCT total score and the potential anchor measure was reviewed for the magnitude of association; in this study, a large effect (i.e., correlation at least 0.5 ) was required [38]. Once established as appropriate, univariate regression analyses accounting for repeated measures were conducted; changes in ADCT total scores from baseline was the dependent variable and changes in the anchor measure from baseline was the independent variable. The change in PGAD and change in DLQI were considered as potential anchor measures and the following anchors were selected a priori: a 1-level improvement in the PGAD; a 4-point improvement on the DLQI total score [39]; or a 1-level improvement in the DLQI band. Patients who were not likely to change were excluded: e.g., reporting PGAD = "excellent" or DLQI = "no effect" (i.e., total score of 0 or 1 ) at baseline. Additional analysis was conducted using the subset of patients whose $\mathrm{AD}$ was considered not controlled at baseline based on the ADCT total score (i.e., score $>7$; Table 1), as established in previous research (Pariser D, Simpson E, Gadkari A, Bieber T, Margolis D, Brown M, Nelson L, Mahajan P, Reaney M, Guillemin I et al: Design, validation and scoring of the Atopic Dermatitis Control Tool (ADCT), unpublished).

For the distribution-based approach, the half standard deviation (SD) method of the baseline ADCT scores, one-third SD, one unit of standard error of measurement (SEM), and two units of SEMs were examined. Final recommendations for thresholds characterizing meaningful within-person change and considered as a clinical important responder were made considering the anchor- and distribution-based results.

\section{Results}

\section{Patient population}

The interim dataset from RELIEVE-AD, as of December 6, 2018, included 1010 patients who completed the baseline survey, 538 patients at Month 1, 458 patients at Month 2, 372 patients at Month 3, and 206 patients at Month 6. Patients who were eligible to receive the survey at each timepoint varied based on time elapsed since they initiated dupilumab. Accounting for the number of surveys sent out at each timepoint, the response rate ranged from between $89.8 \%$ in Month 1 to $74.4 \%$ in Month 6. The smaller sample sizes in the later followups were attributable to many patients not due for survey completion at the time of this interim data cut. Overall, patient characteristics were comparable between patients at baseline and those who had completed the follow-up surveys.

At baseline, the mean age of the patients was 47 years, and the mean age at AD diagnosis was 28 years. More than half of the population (62\%) were female and the majority (74\%) were White. Most patients (96\%) reported experiencing flares over the previous 4 weeks at baseline. The mean skin pain NRS score was 5.9 and the mean DLQI total score was 13.4; no patients reported a DLQI score of 0 or 1 . Very few patients (3.4\%) reported levels of 'excellent' or 'very good' on the PGAD. The mean WPAI-TAI and WPAI-TWI were 45.8 and $40.8 \%$, respectively. The mean ADCT total score was 15.9 at baseline.

\section{Reliability}

Cronbach's $\alpha$ coefficients of the ADCT total score were 0.90 at baseline, 0.93 at Month 1, 0.94 at Month 2, 0.9 at Month 3, and 0.95 at Month 6. Item-to-total correlations ranged from 0.68 to 0.81 at baseline to 0.79 to 0.88 at Month 6 (Table 2). ICCs computed using subgroups of patients with stable PGAD responses were 0.82 for assessments between Months 1 and $2(n=219), 0.78$ 
Table 2 Cronbach's a for internal consistency reliability of ADCT

\begin{tabular}{llllll}
\hline & Baseline $(n=1010)$ & Month 1 $(n=538)$ & Month 2 $(n=458)$ & Month 3 $(n=372)$ & Month 6 ( $(n=206)$ \\
\hline Overall internal consistency & 0.90 & 0.93 & 0.94 & 0.94 & 0.95 \\
Item-to-total correlation & & & 0.81 & 0.81 & 0.84 \\
$\quad$ Overall severity of AD symptoms & 0.74 & 0.79 & 0.79 & 0.79 \\
Days with intense episodes of itching & 0.68 & 0.76 & 0.89 & 0.89 & 0.88 \\
Intensity of bothersomeness & 0.81 & 0.85 & 0.73 & 0.78 & 0.83 \\
Problem with sleep & 0.68 & 0.75 & 0.82 & 0.84 & 0.82 \\
Impact on daily activities & 0.76 & 0.82 & 0.82 & 0.84 & 0.86 \\
Impact on mood or emotions & 0.71 & 0.79 & & & \\
\hline
\end{tabular}

$A D$ Atopic dermatitis, $A D C T$ Atopic Dermatitis Control Tool

between Months 2 and $3(n=189)$, and 0.79 between Months 3 and $6(n=107)$ (Table 3$)$.

\section{Construct validity}

The highest correlations were observed between the ADCT total score and skin pain NRS (from 0.74 to 0.83) and the DLQI total score in the follow-up surveys (from 0.80 to 0.85 ), supporting construct validity (Table 4 ). Spearman's rank-order correlations between the ADCT total score and individual DLQI items ranged between 0.37 (issues at work or studying) and 0.75 (degree of itchiness, soreness, pain or sting) at baseline to 0.12 (issues at work or studying) and 0.75 (degree of itchiness, soreness, pain or sting) at Month 6 . Other item correlations ranged between 0.4 and 0.6 regardless of the timepoint.

\section{Known-group validity}

Known-group analyses indicated that PGAD subgroups with worse AD-related overall well-being had higher mean ADCT total scores (poor AD control) at all timepoints (Table 5). The differences in mean ADCT total score between the adjacent groups were statistically significant $(p<0.01)$, except between 'excellent' and 'very good' at baseline and between 'fair' and 'poor' at Month 6, likely due to small sample sizes. Similarly, patients in the groups of DLQI bands with greater effect on life were associated with higher mean ADCT total scores (poor AD control) (Table 5). All differences in mean ADCT total score between the adjacent bands were statistically significant $(p<0.05)$ except between the small effect and the moderate effect bands at baseline, and

Table 3 Test-retest reliability of ADCT anchored by no change in the Patient Global Assessment of Disease

\begin{tabular}{lll}
\hline & N & ICC $(95 \% \mathrm{Cl})$ \\
\hline ADCT total score at Months 1 and 2 & 219 & $0.82(0.77,0.86)$ \\
ADCT total score at Months 2 and 3 & 189 & $0.78(0.71,0.83)$ \\
ADCT total score at Months 3 and 6 & 107 & $0.79(0.71,0.85)$ \\
\hline
\end{tabular}

ADCT Atopic Dermatitis Control Tool, Cl Confidence interval, ICC Intra-class correlation coefficient between the very large effect and the extremely large effect bands at Month 6. The Cohen's d effect size showed large effect across all adjacent categories except between 'excellent' and 'very good' at baseline, between the small effect and the moderate effect bands at baseline, and between the very large effect and the extremely large effect bands at Month 6.

\section{Ability to detect change (responsiveness)}

Correlational analyses confirmed the ADCT's ability to detect change (responsiveness; Table 6). Specifically, Spearman's rank-order correlation between change in ADCT total score and change in PGAD from baseline ranged from 0.54 in Month 3 to 0.60 in Month 6. Spearman's rank-order correlation between change in ADCT total score and change in DLQI bands from baseline ranged from 0.47 in Month 1 to 0.51 in Month 3. Pearson product-moment correlation between change in ADCT total score and change in DLQI total score from baseline ranged from 0.55 in Month 1 to 0.61 in Month 3 . All correlation coefficients were statistically significant $(p<0.001)$.

\section{Interpretation of change}

Changes in PGAD, DLQI bands, and DLQI total score correlated well with change in ADCT total

Table 4 Construct validity with Spearman's rank-order correlations between ADCT total score and other patientreported outcome measures in RELIEVE-AD

\begin{tabular}{llllll}
\hline & Baseline & Month 1 & Month 2 & Month 3 & Month 6 \\
\hline DLQI total score & $0.543^{* * *}$ & $0.803^{* * *}$ & $0.828^{* * *}$ & $0.846^{* * *}$ & $0.812^{* * *}$ \\
PGAD & $0.489^{* * *}$ & $0.734^{* * *}$ & $0.762^{* * *}$ & $0.758^{* * *}$ & $0.705^{* * *}$ \\
Skin pain & $0.741^{* * *}$ & $0.831^{* * *}$ & $0.807^{* * *}$ & $0.793^{* * *}$ & $0.806^{* * *}$ \\
WPAI-TAI & $0.645^{* * *}$ & $0.677^{* * *}$ & $0.750^{* * *}$ & $0.772^{* * *}$ & $0.706^{* * *}$ \\
WPAI-TWI & $0.605^{* * *}$ & $0.644^{* * *}$ & $0.686^{* * *}$ & $0.721^{* * *}$ & $0.725^{* * *}$ \\
\hline
\end{tabular}

***p $<0.001$

$A D C T$ Atopic Dermatitis Control Tool, DLQ/ Dermatology Life Quality Index, PGAD Patient Global Assessment of Disease, WPAl-TAI Work Productivity and Activity Impairment - Total Activity Impairment, WPAI-TWI Work Productivity and Activity Impairment - Total Work Impairment 
Table 5 Comparisons of mean differences in ADCT total score by PGAD and DLQI known groups

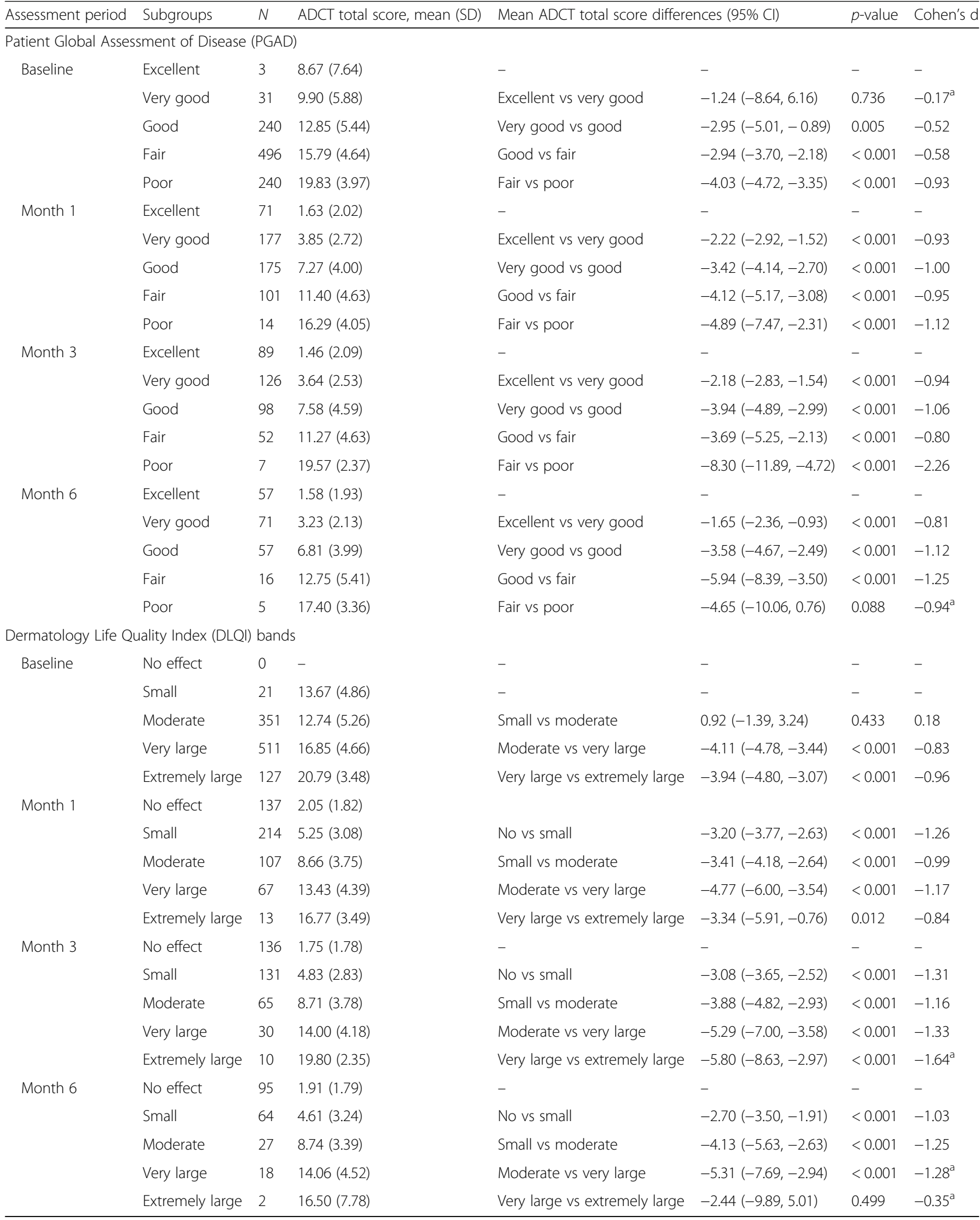


Table 6 Responsiveness of ADCT according to change in Patient Global Assessment of Disease (PGAD) and Dermatology Life Quality Index (DLQI)

\begin{tabular}{ll}
\hline & Correlation coefficient \\
\hline $\begin{array}{l}\text { Change in ADCT total score vs. change } \\
\text { in PGAD }\end{array}$ & Spearman $(95 \% \mathrm{Cl})$ \\
Month 1 vs. Baseline, $n=538$ & $0.56^{* * *}(0.50,0.62)$ \\
Month 2 vs. Baseline, $n=458$ & $0.58^{* * *}(0.51,0.64)$ \\
Month 3 vs. Baseline, $n=372$ & $0.54^{* * *}(0.46,0.61)$ \\
Month 6 vs. Baseline, $n=206$ & $0.60^{* * *}(0.50,0.68)$ \\
Change in ADCT total score vs. change & Spearman $(95 \%$ Cl) \\
in DLQI bands & \\
Month 1 vs. Baseline, $n=538$ & $0.47^{* * *}(0.40,0.54)$ \\
Month 2 vs. Baseline, $n=458$ & $0.48^{* * *}(0.41,0.55)$ \\
Month 3 vs. Baseline, $n=372$ & $0.51^{* * *}(0.43,0.58)$ \\
Month 6 vs. Baseline, $n=206$ & $0.50^{* * *}(0.39,0.59)$ \\
Change in ADCT total score vs. change & Pearson $(95 \%$ Cl) \\
in DLQI total score & \\
Month 1 vs. Baseline, $n=538$ & $0.55^{* * *}(0.49,0.61)$ \\
Month 2 vs. Baseline, $n=458$ & $0.57^{* * *}(0.50,0.63)$ \\
Month 3 vs. Baseline, $n=372$ & $0.61^{* * *}(0.54,0.67)$ \\
Month 6 vs. Baseline, $n=206$ & $0.60^{* * *}(0.51,0.68)$ \\
\hline ***p 0.001 & \\
ADCT Atopic Dermatitis Control Tool, Cl confidence interval
\end{tabular}

score $(r>0.50)$; therefore, PGAD and DLQI were determined to be appropriate anchors. Through the anchor-based approach, 1-level improvement in PGAD or in DLQI bands, or a 4-point reduction in DLQI total score, was associated with a reduction in ADCT total score of $5.30,5.20$, or 3.90 , respectively, among the overall sample, and 5.43, 5.42, or 4.03, respectively, among patients with uncontrolled $\mathrm{AD}$ symptoms at baseline (Table 7).

Using the distribution-based approach, the half SD and one-third SD of ADCT total score at baseline were 2.72 and 1.81, respectively. The SEM of ADCT total score at baseline was 1.71 when using the overall Cronbach's $\alpha$ at baseline as reliability measure and 2.32 when using the ICC between Month 1 and Month 2 as reliability measure. Consequently, 2 units of SEM were 3.42 and 4.64, respectively.

\section{Discussion}

Practice guidelines recommend that during a clinical evaluation, clinicians inquire about a patient's itch, sleep, and impact on daily activity due to their AD [15]. However, no single PROM is currently available to holistically evaluate these concepts within a single tool. The ADCT was previously developed and validated to assess AD control, with the standards recommended in the PRO Guidance by the US Food and Drug Administration [40]. Not only does this PROM evaluate AD control in a comprehensive and standardized approach, but, at the same time, it can easily be completed at home or during a clinical encounter given its brevity and ability to be self-administered via paper, online, or handheld device. The ADCT is brief, straightforward, and easily scored and interpreted, providing an immediate metric to patient self-measure of their disease control, and is thus very well adapted to clinical practice. It is anticipated that the ADCT will also facilitate meaningful patient-clinician dialogue about disease control, enhancing clinical monitoring and informing treatment decisions.

The measurement properties of the ADCT based on initial evaluations have been previously published (Pariser D, Simpson E, Gadkari A, Bieber T, Margolis D, Brown M, Nelson L, Mahajan P, Reaney M, Guillemin I et al: Design, validation and scoring of the Atopic Dermatitis Control Tool (ADCT), unpublished); in the present study, we have further evaluated this novel PROM based on data from RELIEVE-AD, a real-world, prospective, longitudinal patient survey. Cross-sectional properties previously defined were confirmed within this longitudinal context. Internal consistency was met, and moreover, ICCs computed using subgroups of patients with stable PGAD responses supported the test-retest reliability of the ADCT total score. High correlations between the ADCT and DLQI and skin pain NRS supported convergent validity, while known-groups validity was shown on PGAD subgroups with worse AD-related overall wellbeing and in the groups of DLQI bands with greater effect on life having higher mean ADCT total scores at all timepoints. Separately, versus the DLQI, the ADCT was not strongly correlated with the item "impact at work or studying" but was strongly correlated with

Table 7 Average reduction in ADCT total score by improvement in Patient Global Assessment of Disease (PGAD) and Dermatology Life Quality Index (DLQI)

\begin{tabular}{|c|c|c|c|c|}
\hline & \multicolumn{2}{|c|}{ Overall sample } & \multicolumn{2}{|c|}{ Uncontrolled patients (ADCT $\geq 7$ at baseline) } \\
\hline & $\bar{N}$ & Mean reduction & $\bar{N}$ & Mean reduction \\
\hline Reduction in ADCT total score per 1-level improvement in PGAD ${ }^{a}$ & 1570 & $5.30^{* * *}(5.14,5.46)$ & 1479 & $5.43^{* * *}(5.27,5.59)$ \\
\hline Reduction in ADCT total score per 1-level improvement in DLQI bands ${ }^{\mathrm{b}}$ & 1574 & $5.20^{* * *}(5.05,5.35)$ & 1483 & $5.42^{* * *}(5.27,5.58)$ \\
\hline Reduction in ADCT total score per 4-point improvement in DLQI total score ${ }^{b}$ & 1574 & $3.90^{* * *}(3.80,4.00)$ & 1483 & $4.03^{* * *}(3.92,4.12)$ \\
\hline
\end{tabular}

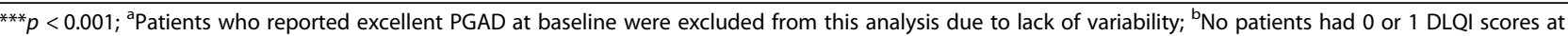
baseline and therefore no patients were excluded from this analysis

ADCT Atopic Dermatitis Control Tool 
"impact on social or leisure activities" at each of the timepoints. Analyses revealed a very strong correlation with the item "degree of itchiness, soreness, pain or sting". The total scores were as well strongly correlated. From these findings, it appears that self-perception of disease control is not strongly associated with AD impact at work or studying but it is very strongly with HRQL.

The ability of the ADCT to detect change was confirmed for use in real-world settings; the threshold for meaningful within-person change was estimated to be 5 points. Establishing this threshold allows the clinician to assess clinically meaningful changes in AD control over time based on repeated administration of the ADCT. As previously established, a total score of $\geq 7$ on the ADCT allows a cross-sectional assessment of lack of AD control at a given timepoint (Pariser D, Simpson E, Gadkari A, Bieber T, Margolis D, Brown M, Nelson L, Mahajan P, Reaney M, Guillemin I et al: Design, validation and scoring of the Atopic Dermatitis Control Tool (ADCT), unpublished). The meaningful within-person change threshold of 5 points compliments this by allowing a longitudinal assessment of improvement in disease control of a patient over time. Finally, good stability of the ADCT in providing reliable data over time was observed through test-retest scores against subgroups of patients with stable PGAD responses.

In consideration of our positive findings on the validity and reliability of the ADCT, a few study limitations are to be noted. First, participant diagnosis of AD relied only on self-report (i.e., not confirmed by a clinician). However, all included patients were prescribed dupilumab, which was approved only for AD when patients were enrolled in the study. Regarding the sample size, the RELIEVE-AD study is ongoing, and the full dataset is still maturing; therefore, there was a reduction of patient numbers across follow-up periods that was mainly due to the number of patients who were eligible for survey completion at those timepoints by the December 6, 2018 data cut.

While our results confirmed the psychometric properties of ADCT using data from an ongoing observational, prospective, longitudinal patient survey study, additional studies that are currently ongoing will also be able to confirm the present findings and potentially address some of the limitations. For example, one study is currently ongoing including patients and physicians to determine how ADCT compares with clinical scales (e.g., Eczema Area and Severity Index, physician assessment of control). We expect that data from such a study will also be able to confirm our findings within a population of patients with physician-confirmed diagnosis of AD.

Despite the limitations, the real-world survey data used in the present study have added further evidence to initial evaluations that the ADCT is a valid and reliable tool for assessing patient-perceived AD control and may provide a useful patient-clinician communication tool on disease control in clinical and non-clinical settings.

\section{Conclusion}

Our findings confirm that the ADCT is a valid and reliable tool for assessing AD control in real-world, longitudinal settings. In addition, ongoing studies will be able to further evaluate the present findings and potentially address some of the limitations noted.

\section{Abbreviations \\ AD: Atopic dermatitis; ADCT: Atopic Dermatitis Control Tool; Cl: Confidence interval; DLQI: Dermatology Life Quality Index; HRQL: Health-related quality of life; ICC: Intra-class correlation; NRS: Numerical Rating Scale; PCC: Pearson correlation coefficient; PGAD: Patient Global Assessment of Disease; \\ POEM: Patient-Oriented Eczema Measure; PROM: Patient-reported outcome measure; RELIEVE-AD: EaRly REal-WorLd Patlent EValuation for DupixEnt in Atopic Dermatitis; SD: Standard deviation; SEM: Standard error of measurement; WPAI-AD: Work Productivity and Activity Impairment - Atopic Dermatitis; WPAI-TAI: WPAI total activity impairment; WPAI-TWI: WPAI total work impairment}

\section{Acknowledgments}

The authors and study sponsors wish to thank study participants enrolled in the Patient Support Program. Medical writing support provided by Gauri Saal, MA Economics, of Prime, Knutsford, Cheshire, UK, and was funded by Sanofi and Regeneron Pharmaceuticals, Inc.

\section{Authors' contributions}

$L E, A G, U G M, M R, P M, I G, E S, M B$, DP contributed to the conception, design, and interpretation of the data. MY. LN, MB contributed to the conception, design, acquisition, analysis, and interpretation of the data. All authors read and approved the final manuscript to be published after critically revising it for important intellectual content

\section{Funding}

The study was funded by Sanofi and Regeneron Pharmaceuticals, Inc. The funders contributed to the design of the study, to the collection, analysis and interpretation of data, and to the writing of the manuscript.

\section{Availability of data and materials}

The datasets generated and/or analysed during the current study are not publicly available as the RELIEVE-AD study is ongoing with continued data collection, but are available from the corresponding author on reasonable request.

Ethics approval and consent to participate

Patients must have consented online to participate in the real-world study prior to proceeding to completing the baseline questions through a secure online portal. The survey was performed in accordance with the Helsinki Declaration of 1964 and its later amendments and received a full review approval by the New England Independent Review Board in December 2017.

\section{Consent for publication}

Not applicable.

\section{Competing interests}

L. Eckert, M. Reaney, I Guillemin, U.G. Mallya, and P. Mahajan are employees and shareholders of Sanofi. A. Gadkari is an employee and shareholder of Regeneron. M. Yang is an employee of the Analysis Group, Inc. which received research funding for the current study. L. Nelson and M. Brown are employees of RTI Health Solutions, which received research funding for the current study. E.L. Simpson has received grants/research support from Amgen, Celgene, Chugai, Galderma, and Regeneron Pharmaceuticals Inc., and is a consultant for Anacor, Asubio, Celgene, Galderma, Genentech, Medicis, and Merck. D.M. Pariser has been a consultant to Abbott Laboratories, Amgen, Asana, Biosciences, LLC, Atacama Therapeutics, Bickel 
Biotechnology, Biofrontera AG, Celgene Corporation, Dermira, Dermavant Sciences, DUSA Pharmaceuticals, Inc., Eli Lilly and Company, LEO Pharma, US, Merck \& Co., Inc., Novartis Pharmaceuticals Corp., Novo Nordisk A/S, Ortho Dermatologics, Peplin Inc., Pfizer Inc., Photocure ASA, Promius Pharmaceuticals, Regeneron Pharmaceuticals, Inc., Sanofi, Stiefel a GSK company, TDM SurgiTech, Inc., TheraVida, Valeant Pharmaceuticals International. M Boguniewicz has received grants from Regeneron Pharmaceuticals, Inc. and has been a consultant for Regeneron Pharmaceuticals, Inc. and Sanofi-Genzyme.

\section{Author details}

${ }^{1}$ Oregon Health and Science University, Portland, OR, USA. ${ }^{2}$ Sanofi, France, Chilly-Mazarin, Paris, France. ${ }^{3}$ Regeneron Pharmaceuticals, Inc, Tarrytown, NY, USA. ${ }^{4}$ Sanofi, Cambridge, MA, USA. ${ }^{5}$ Analysis Group, Boston, MA, USA. ${ }^{6}$ RTI Health Solutions, Research Triangle Park, NC, USA. ${ }^{7}$ Sanofi, Guildford, UK. ${ }^{8}$ Sanofi, Bridgewater, NJ, USA. 'S School of Medicine, University of Colorado, Boulder, CO, USA. ${ }^{10}$ Eastern Virginia Medical School, Norfolk, VA, USA.

\section{Received: 21 May 2019 Accepted: 10 October 2019}

\section{Published online: 06 November 2019}

\section{References}

1. Brunner PM, Silverberg Jl, Guttman-Yassky E, Paller AS, Kabashima K, Amagai $M$, et al. Increasing comorbidities suggest that atopic dermatitis is a systemic disorder. J Invest Dermatol. 2017;137(1):18-25.

2. Thijs JL, Strickland I, Bruijnzeel-Koomen C, Nierkens S, Giovannone B, Knol $\mathrm{EF}$, et al. Serum biomarker profiles suggest that atopic dermatitis is a systemic disease. J Allergy Clin Immunol. 2018;141(4):1523-6.

3. Bieber T. Atopic dermatitis. Ann Dermatol. 2010;22(2):125-37.

4. Boguniewicz M, Leung DY. Atopic dermatitis: a disease of altered skin barrier and immune dysregulation. Immunol Rev. 2011;242(1): 233-46.

5. Guttman-Yassky E, Nograles KE, Krueger JG. Contrasting pathogenesis of atopic dermatitis and psoriasis--part I: clinical and pathologic concepts. $J$ Allergy Clin Immunol. 2011;127(5):1110-8,

6. Simpson EL, Guttman-Yassky E, Margolis DJ, Feldman SR, Qureshi A, Hata T, et al. Association of inadequately controlled disease and disease severity with patient-reported disease burden in adults with atopic dermatitis. JAMA Dermatol. 2018:154(8):903-12

7. Barbarot S, Auziere S, Gadkari A, Girolomoni G, Puig L, Simpson EL, et al. Epidemiology of atopic dermatitis in adults: results from an international survey. Allergy. 2018;73:1284-93.

8. Girolomoni G, Gadkari A, Auziere S, Puig L, Barbarot S, Chosidow O, et al. The patient-reported disease burden in adults with atopic dermatitis: a cross-sectional study in Canada and Europe. Value Health. 2017;20(9):A807.

9. Dalgard FJ, Gieler U, Tomas-Aragones L, Lien L, Poot F, Jemec GBE, et al. The psychological burden of skin diseases: a cross-sectional multicenter study among dermatological out-patients in 13 European countries. J Invest Dermatol. 2015;135(4):984-91.

10. Simpson EL, Bieber T, Eckert L, Wu R, Ardeleanu M, Graham NM, et al. Patient burden of moderate to severe atopic dermatitis (AD): insights from a phase $2 \mathrm{~b}$ clinical trial of dupilumab in adults. J Am Acad Dermatol. 2016; 74(3):491-8.

11. Yano C, Saeki H, Ishiji T, Ishiuji Y, Sato J, Tofuku Y, et al. Impact of disease severity on work productivity and activity impairment in Japanese patients with atopic dermatitis. J Dermatol. 2013;40(9):736-9.

12. Whiteley J, Emir B, Seitzman R, Makinson G. The burden of atopic dermatitis in US adults: results from the 2013 National Health and wellness survey. Curr Med Res Opin. 2016;32:1645-51.

13. Sandhu JK, Wu KK, Bui TL, Armstrong AW. Association between atopic dermatitis and suicidality: a systematic review and meta-analysis. JAMA Dermatol. 2019;155(2):178-87.

14. Bender BG, Ballard R, Canono B, Murphy JR, Leung DY. Disease severity, scratching, and sleep quality in patients with atopic dermatitis. J Am Acad Dermatol. 2008;58(3):415-20.

15. Eichenfield LF, Tom WL, Chamlin SL, Feldman SR, Hanifin JM, Simpson EL, et al. Guidelines of care for the management of atopic dermatitis: section 1. Diagnosis and assessment of atopic dermatitis. J Am Acad Dermatol. 2014; 70(2):338-51.
16. Chalmers JR, Thomas KS, Apfelbacher C, Williams HC, Prinsen CA, Spuls PI, et al. Report from the fifth international consensus meeting to harmonize core outcome measures for atopic eczema/dermatitis clinical trials (HOME initiative). Br J Dermatol. 2018;178(5):e332-41.

17. Schmitt J, Spuls P, Boers M, Thomas K, Chalmers J, Roekevisch E, et al. Towards global consensus on outcome measures for atopic eczema research: results of the HOME II meeting. Allergy. 2012;67(9):1111-7.

18. Leung DY, Guttman-Yassky E. Assessing the current treatment of atopic dermatitis: unmet needs. J Allergy Clin Immunol. 2017;139(4S):S47-8.

19. European Task Force on Atopic Dermatitis. Severity scoring of atopic dermatitis: the SCORAD index. Consensus report of the European task force on atopic dermatitis. Dermatology. 1993;186(1):23-31.

20. Wei W, Anderson P, Gadkari A, Blackburn S, Moon R, Piercy J, et al. Discordance between physician- and patient-reported disease severity in adults with atopic dermatitis: a US cross-sectional survey. Am J Clin Dermatol. 2017;18(6):825-35.

21. Schmitt J, Spuls PI, Thomas KS, Simpson E, Furue M, Deckert S, et al. The Harmonising outcome measures for eczema (HOME) statement to assess clinical signs of atopic eczema in trials. J Allergy Clin Immunol. 2014;134(4): 800-7.

22. Yosipovitch G, Eckert L, Chen Z, Ardeleanu M, Shumel B, Plaum S, et al. P480 correlations of itch with quality of life and signs of atopic dermatitis across dupilumab trials. Ann Allergy Asthma Immunol. 2017;119(5):S95.

23. Charman CR, Venn AJ, Williams HC. The patient-oriented eczema measure: development and initial validation of a new tool for measuring atopic eczema severity from the patients' perspective. Arch Dermatol. 2004;140(12):1513-9.

24. Finlay AY, Khan GK. Dermatology Life Quality Index (DLQI)- a simple practical measure for routine clinical use. Clin Exp Dermatol. 1994;19:210-6.

25. Zuberbier T, Orlow SJ, Paller AS, Taieb A, Allen R, Hernanz-Hermosa JM, et al. Patient perspectives on the management of atopic dermatitis. J Allergy Clin Immunol. 2006;118(1):226-32.

26. Reitamo S, Allsopp R. Treatment with twice-weekly tacrolimus ointment in patients with moderate to severe atopic dermatitis: results from two randomized, multicentre, comparative studies. J Dermatolog Treat. 2010;21(1):34-44.

27. Ortiz de Frutos FJ, Torrelo A, de Lucas R, Gonzalez MA, Alomar A, Vera A, et al. Patient perspectives on triggers, adherence to medical recommendations, and disease control in atopic dermatitis: the DATOP study. Actas Dermosifiliogr. 2014;105:487-96.

28. Meurer M, Lubbe J, Kapp A, Schneider D. The role of pimecrolimus cream 1\% (Elidel) in managing adult atopic eczema. Dermatology. 2007;215(Suppl 1):18-26.

29. Abuabara K, Hoffstad O, Troxel A, Gelfand JM, Margolis DJ. Atopic dermatitis disease control and age: a cohort study. J Allergy Clin Immunol. 2015;136(1): 190-2 e193.

30. Dupixent ${ }^{\oplus}$ [dupilumab injection for subcutaneous use] prescribing information. https://www.accessdata.fda.gov/drugsatfda_docs/label/2017/ 761055lbl.pdf. Accessed 2 Apr 2019

31. Dupixent (dupilumab). Summary of Product Characteristics. European Medicines Agency 2017. http://www.ema.europa.eu/docs/en GB/ document_library/EPAR___Product_Information/human/004390/WC5002365 07.pdf. Accessed 2 Apr 2019.

32. Cortina J. What is coefficient alpha? An examination of theory and applications. J Appl Psychol. 1993;78(1):98.

33. Shrout PE, Fleiss JL. Intraclass correlations: uses in assessing rater reliability. Psychol Bull. 1979;86(2):420-8.

34. Terwee CB, Bot SD, de Boer MR, van der Windt DA, Knol DL, Dekker J, et al. Quality criteria were proposed for measurement properties of health status questionnaires. J Clin Epidemiol. 2007;60(1):34-42.

35. Cohen J. A power primer. Psychol Bull. 1992;112(1):155-9.

36. Hongbo Y, Thomas CL, Harrison MA, Salek MS, Finlay AY. Translating the science of quality of life into practice: what do dermatology life quality index scores mean? J Invest Dermatol. 2005;125(4):659-64.

37. Durlak JA. How to select, calculate, and interpret effect sizes. J Pediatr Psychol. 2009;34(9):917-28.

38. Streiner DL, Norman GR, Cairney J. Health measurement scales: a practical guide to their development and use. 5th ed. New York: Oxford University Press; 2015.

39. Basra MK, Salek MS, Camilleri L, Sturkey R, Finlay AY. Determining the minimal clinically important difference and responsiveness of the dermatology life quality index (DLQI): further data. Dermatology. 2015; 230(1):27-33. 
40. US Food and Drug Administration. Guidance for Industry Patient-Reported Outcome Measures: Use in Medical Product Development to Support Labeling Claims. (2009). https://www.fda.gov/regulatory-information/searchfda-guidance-documents/patient-reported-outcome-measures-use-medicalproduct-development-support-labeling-claims. Accessed 2 Apr 2019.

\section{Publisher's Note}

Springer Nature remains neutral with regard to jurisdictional claims in published maps and institutional affiliations.

Ready to submit your research? Choose BMC and benefit from:

- fast, convenient online submission

- thorough peer review by experienced researchers in your field

- rapid publication on acceptance

- support for research data, including large and complex data types

- gold Open Access which fosters wider collaboration and increased citations

- maximum visibility for your research: over $100 \mathrm{M}$ website views per year

At $\mathrm{BMC}$, research is always in progress.

Learn more biomedcentral.com/submissions 